\title{
Regional Household Economic Stress and Retail Sales Fluctuations
}

\author{
Thomas M. Fullerton, Jr. (Corresponding author) \\ Department of Economics \& Finance, University of Texas at El Paso, El Paso, TX, USA \\ Tel: 915-747-7747Ｅ-mail: tomf@utep.edu
}

Ana P. Gutiérrez-Zubiate

Department of Economics \& Finance, University of Texas at El Paso, El Paso, TX, USA

Received: May 15, 2020 Accepted: June 13, 2020 Published: June 23, 2020

doi:10.5296/ber.v10i3.16875 URL: https://doi.org/10.5296/ber.v10i3.16875

\begin{abstract}
Economic stress indices are used to monitor business cycle conditions in several regions. Although the deployment of these tools is spreading, there have been relatively few efforts to empirically assess the performance of these gauges, especially at the regional level. This study takes advantage of one such index that is published monthly and has more than 15 years of historical data. Results obtained confirm an inverse relationship between household economic duress and retail sales activity, but it is not found to be statistically reliable over the long-run. Deviations from equilibrium are found to last for 142 months. More relevantly, a 1 -point increase in the index is associated with a $\$ 3.48$ million decline in total commercial activity. Additional testing using data for other regions and/or economic variables appears warranted. Empirical analysis that examines additional potential short-run linkages for El Paso may also prove useful.
\end{abstract}

Keywords: Economic Stress Index, Regional Economics, Retail Sales, Time Series Analysis

JEL Categories: R15, Regional Econometrics, M21, Business Economics

\section{Introduction}

The Misery Index for the United States national economy is designed to provide a measure of household economic difficulty. That index is calculated by adding the annual percentage change in the consumer price index to the seasonally adjusted unemployment rate (Di Tella et al., 2001). Although there is widespread recognition that inflation and unemployment affect consumer sentiment, the original misery index overlooks financial conditions that are 
important to households (Lovell and Tien, 2000). Dye and Sutherland (2009) addresses that issue by introducing housing prices to the framework. The latter measure subtracts percentage changes in housing prices from the original misery index and is known as the Household Economic Stress Index.

The intuition underlying the household economic stress index is fairly straightforward. Inflation erodes consumer purchasing power, unemployment causes personal incomes to fall, and falling housing prices reduce household wealth. Consequently, upward movements in the household economic stress index are associated with higher levels of household economic stress. Conversely, downward movements of the household economic stress index occur when national economic conditions improve.

While there have been a number of studies that examine the performance of these types of measures for national economies (Tang and Lean, 2009; Hanke, 2014), comparatively little research of this nature has been conducted for regional economies. This effort attempts to partially fill that gap in the applied economics literature paper by estimating a household economic stress index for the El Paso metropolitan economy (HESI). In addition to calculating monthly values for HESI, empirical analysis is used to quantify the relationship between the new index and local retail activity. The latter is selected because regional commerce is likely to be directly impacted by changes in household economic tensity.

Subsequent sections of study are as follows. A review of prior research on related topics is provided in the second section. A description of the sample data collected and the methodology employed follow. Empirical results obtained are then discussed. A concluding section summarizes the results obtained and offers suggestions for future research. A historical data appendix is included at the end of the study.

\section{Literature Review}

The misery index is calculated by a simple sum of two variables, the annual rate of change in consumer prices and the unemployment rate. This index has long been used politicians to deride the records of predecessors. It has also been found to be helpful in analyzing economic problems such as crime and policy effectiveness (Tang and Lean, 2009; Lean and Smyth, 2011).

Changes to the basic index have periodically been attempted. Barro (1999) modifies the original misery index by adding the 30-year government bond and the output gap for the real gross domestic product (GDP). That modification was employed as a device for grading presidential policy effectiveness in the United States. Hanke (2014) adjusts the index so that it can be used to assess economic conditions throughout the global economy. The latter identity sums inflation, unemployment, and commercial bank lending rates and subtracts the percentage change in real per capita GDP. Increases in the index reflect worsening misery or deteriorating economic conditions. Decreases in the index occur when economic well-being is improving and misery is subsiding.

A separate analysis of economic sentiment modified the original index by including housing prices in the identity. Hufbauer et al. (2008) do so as a means for examining presidential 
approval ratings. When housing prices increase, consumers, and registered voters, are likely to feel more confident. Voters will generally feel less confident when housing prices fall because that frequently reflects a weakening economy.

Dye and Sutherland (2009) use a variant of the latter approach because it reasonably assumes that household economic stress is influenced by wealth. Housing is an important component of wealth (Grinstein-Weiss et al., 2013) and the augmented misery index may better reflect changes in housing wealth. The amplified index is calculated by subtracting the change in housing prices from the original misery index sum of inflation plus unemployment. Regional variants of the household economic stress index are also used as gauges of local economic conditions for several different geographic areas in the United States (CEDBR, 2017; Fullerton et al., 2019).

This type of index analysis is being applied to a growing number of countries around the globe, primarily using macroeconomic data (Layton, 1992; Akcay, 2018; Dadgar and Nazari, 2018). An exception to this general pattern is the study of local election outcomes in France (Farvaque and Jean, 2007). Another study within this group that is noteworthy is Hortalá i Arau and Rey Miró (2011). That effort estimates a modified economic stress index by summing inflation and unemployment rates, and then subtracting the GDP growth rate. In the material below, the percentage change in housing prices is employed rather than GDP or income percentage changes. That choice is made because, similar to unemployment and inflation, local housing prices tend to be reported on a monthly basis in much of the United States.

As noted above, relatively little econometric research has been conducted using national misery measures and even less has been completed for regional household stress gauges. This study attempts to partially fill that gap in the applied economics literature by taking advantage of a regional household economic stress index for the El Paso metropolitan economy. Monthly historical data for the El Paso index are calculated by the University of Texas at El Paso Border Region Modeling Project (UTEP BRMP). The sample covers a full business cycle, allowing a realistic analysis of whether the stress index provides a useful tool for monitoring local economic conditions.

\section{Data and Methodology}

Monthly data for El Paso HESI and retail sales are used for the study. Prior to the empirical analysis, the sales data are divided by the United States personal consumption expenditures price deflator and the population of El Paso County. Those steps are taken to create a real per capita retail sales (RSPC) variable. To examine the potential links between household economic stress and retail conditions, an autoregressive distributed lag (ARDL) modeling framework is employed (Pesaran et al., 2001). Such an approach is useful because it allows for cases in which potentially cointegrated variables can follow I(1), I(0), or a mix of those two patterns. The sample data are from December 2002 through January 2018. The sample period is determined by the availability of complete retail sales data for El Paso.

The dependent variable for this study is El Paso real per capita retail sales (RSPC). Real retail 
sales are reported in millions of dollars at a quarterly frequency by the Federal Reserve Bank of Dallas Regional (FRBD, 2019). The quarterly real retail sales data are used to generate a monthly frequency variable using cubic spline interpolation (CE, 2010). To convert the aggregate real retail sales data to per capita real retail sales, monthly population estimates are required. A cubic spline interpolation procedure is also applied to annual population data for El Paso County. RSPC results from dividing the monthly real retail sales estimates by the monthly population estimates. The monthly historical data for HESI are from the University of Texas at El Paso Border Region Modeling Project (Fullerton et al., 2019).

Table 1. Summary Statistics

\begin{tabular}{|l|l|l|}
\hline & RSPC & HESI \\
\hline Number of Observations & 182 & 182 \\
\hline Mean & $\$ 1,180.88$ & 5.6 \\
\hline Median & $\$ 1,189.39$ & 6.1 \\
\hline Standard Deviation & $\$ 57.72$ & 5.1 \\
\hline Maximum & $\$ 1,272.85$ & 15.4 \\
\hline Minimum & $\$ 1,046.50$ & -10.2 \\
\hline Skewness & -0.521 & -1.224 \\
\hline Kurtosis & 2.304 & 4.622 \\
\hline Coefficient of Variation & 0.049 & 0.91 \\
\hline
\end{tabular}

Notes:

Sample Period is December 2002 to January 2018.

RSPC is El Paso Real Per Capita Retail Sales in 2019Q1 \$US.

Quarterly RS are from the Federal Reserve Bank of Dallas (FRBD).

HESI is the El Paso Household Economic Stress Index of the UTEP BRMP.

Table 1 reports summary statistics for both variables. As previously mentioned, retail sales are converted to real dollars using the United States personal consumption expenditures price index with the first quarter of 2019 selected as the base period (BEA, 2019). That series is then converted to a per capita equivalent by dividing it by the monthly population estimates discussed in the prior section. The sample period average for RSPC is $\$ 1,180.88$ constant 2019Q1 dollars, with a median of $\$ 1,189.39$, and a standard deviation of $\$ 57.72$. The minimum value for RSPC is $\$ 1,046.50$ and occurs in April 2009. The RSPC maximum of $\$ 1,272.85$ dollars occurs in December 2005. The latter two data points yield a range of $\$ 226.35$. Because the left tail of the data is longer than the right tail, RSPC is slightly left-skewed with a skewness coefficient of -0.521 . Relative to a normal distribution, RSPC is slightly platykurtic with somewhat heavy tails and a kurtosis coefficient of 2.304. Because the RSPC data are tightly clustered and the standard deviation is small compared to the mean, the coefficient of variation is 0.049 . 
The sample period average for HESI is 5.6, with a median of 6.1, and a standard deviation of 5.1. Maximum economic stress occurred in March 2010 when HESI reached 15.4. The minimum value of -10.2 was observed in September 2006, yielding a range of 25.6 over the course of the sample period. As with RSPC, HESI has a negative skewness (-1.224) coefficient that results from an asymmetric distribution of the data for this variable. The fourth moment coefficient of 4.622 indicates that the data for HESI leptokurtic and have a relatively high peak compared to what would be observed for a Gaussian distribution. In spite of the latter, the standard deviation is almost equal to the mean and the coefficient of variation for HESI is 0.91 . While the tails for HESI are fairly thin, the range is wide and this variable has a larger coefficient of variation than RSPC.

Equation (1) illustrates how the original misery index for the United States national economy is calculated. MI stands for the index. CPI12 is the 12-month change in the national consumer price index. UR is the seasonally adjusted national unemployment rate. The subscript $t$ is a time period index for each month. When economic conditions worsen, MI (misery) tends to rise. When economic conditions improve, MI tends to decline.

$$
\mathrm{MI}_{\mathrm{t}}=\mathrm{CPI} 12_{\mathrm{t}}+\mathrm{UR}_{\mathrm{t}}
$$

Equation (2) shows how the El Paso household economic stress index is calculated. HESI $\mathrm{t}_{\mathrm{t}}$ is the El Paso index value for month t. As in Equation (1), CPI12 is the 12-month change in the national consumer price index. MA12(ELPUR $)$ is a 12-month moving average of the local unemployment rate through month $\mathrm{t}$. Because a 12-month moving average is utilized, it is not necessary to use seasonally adjusted values for this variable. MA12(ELPHP $)$ is a 12-month moving average of the 12-month percentage change of the median price for existing single-family houses in El Paso up through month t. Historical data for HESI and the individual components are taken from Fullerton et al. (2019).

$$
\mathrm{HESI}_{\mathrm{t}}=\mathrm{CPI} 12_{\mathrm{t}}+\mathrm{MA}_{2}\left(\mathrm{ELPUR}_{\mathrm{t}}\right)-\mathrm{MA} 2\left(\mathrm{ELPHP}_{\mathrm{t}}\right)
$$

An ARDL approach is an attractive alternative that allows estimating both short-term and long-term relationships between the variables. ARDL models can include lags of the dependent variable as well as lags of the explanatory variables. Equation (3) provides a basic version of an ARDL specification for real retail sales per capita (RSPC) as a function of the household economic stress (HESI) in El Paso.

$$
\mathrm{RSPC}_{\mathrm{t}}=\beta_{0}+\beta_{1} \mathrm{RSPC}_{\mathrm{t}-1}+\ldots+\beta_{\mathrm{p}} \mathrm{RSPC}_{\mathrm{t}-\mathrm{p}}+\mathrm{a}_{1} \operatorname{HESI}_{\mathrm{t}-1}+\ldots+\mathrm{a}_{\mathrm{q}} \mathrm{HESI}_{\mathrm{t}-\mathrm{q}}+\mathrm{U}_{\mathrm{t}}
$$

Equation (4) is an example of an $\operatorname{ARDL}(p, q)$ specification that assumes that $\mathrm{RSPC}_{t}$ and $\mathrm{HESI}_{\mathrm{t}}$ are both stationary and uncorrelated with $\mathrm{U}_{\mathrm{t}}$. As long as those assumptions are satisfied, ordinary least squares parameter estimation will be consistent. Cointegration can be tested using a bounds test (Pesaran et al., 2001). That test requires using a first difference operator, $\Delta$, with a random error term, $V_{t}$ as shown below. In Equation (4), the $\gamma_{i}$ and $\lambda_{j}$ coefficients are short-run parameters, while the $\delta_{\mathrm{i}}$ and $\theta_{\mathrm{j}}$ coefficients represent long-run parameters. For the time subscripts, $i=1,2, \ldots, p$ and $j=1,2, \ldots, q$.

$$
\Delta \mathrm{RSPC}_{\mathrm{t}}=\gamma_{0}+\gamma_{1} \Delta \mathrm{RSPC}_{\mathrm{t}-1}+\ldots+\gamma_{\mathrm{p}} \Delta \mathrm{RSPC}_{\mathrm{t}-\mathrm{p}}+\lambda_{1} \Delta \mathrm{HESI}_{\mathrm{t}-1}+\ldots+\lambda_{\mathrm{q}} \Delta \mathrm{HESI}_{\mathrm{t}-\mathrm{q}}+\delta_{1} \mathrm{RSPC}_{\mathrm{t}-1}
$$




$$
+\ldots+\delta_{\mathrm{p}} \mathrm{RSPC}_{\mathrm{t}-\mathrm{p}}+\theta_{1} \mathrm{HESI}_{\mathrm{t}-1}+\ldots+\theta_{\mathrm{q}} \mathrm{HESI}_{\mathrm{t}-\mathrm{q}}+\mathrm{V}_{\mathrm{t}}
$$

$\mathrm{RSPC}_{\mathrm{t}}$ is hypothesized to be negatively correlated with HESI $\mathrm{H}_{\mathrm{t}}$. If economic stress intensifies, it is because unemployment increases, inflation accelerates, or housing prices decline. When joblessness goes up, incomes decline. Inflation erodes consumer purchasing power. Housing price decrements reduce household wealth. Consequently, any increases in HESI will tend to reduce commercial sales volumes, while drops in HESI will, typically, lead to increases in RSPC.

\section{Empirical Results}

Given the manner in which HESI is calculated, HESI and RSPC should be inversely correlated. The scatterplot in Figure 1 seemingly offers evidence in favor of that hypothesis. The regression line, shown in red, has a discernible downward slope. The relationship may not be very reliable and the graph appears to contain a fair amount of "noise." For that reason, more careful empirical scrutiny is warranted.

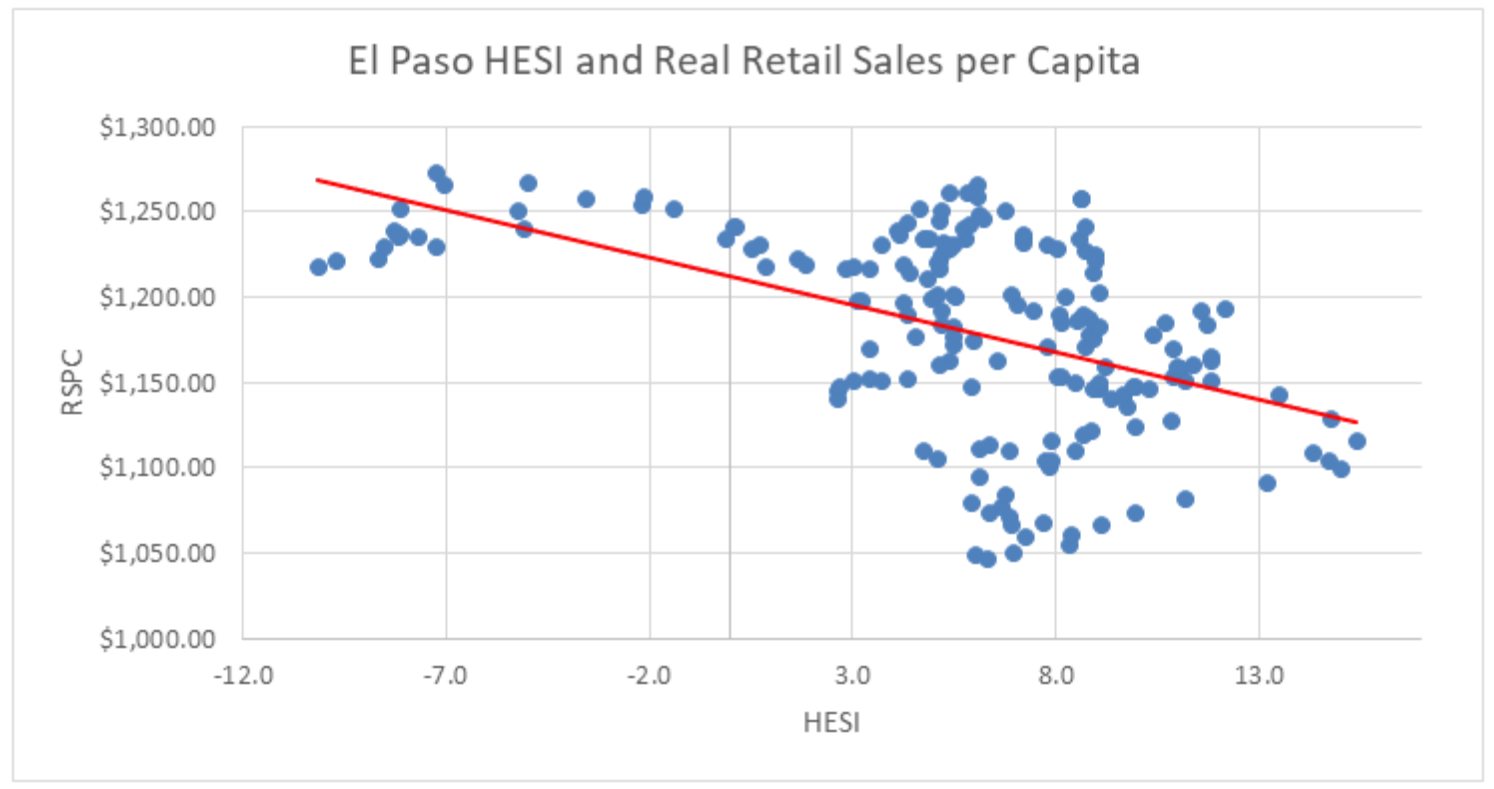

Figure 1. El Paso Real Retail Sales per Capita vs. HESI

Table 2 reports ARDL estimation results with RSPC as the dependent variable. The specification includes 12 autoregressive lags and 12 dynamic lags. The lag structure $(\mathrm{p}=12$, $\mathrm{k}=12$ ) is determined using the Akaike information criterion. The lag structure selected also yields the lowest Hannan-Quinn and Schwarz information criteria. This specification further generates the highest log likelihood statistic. The HESI coefficients in Table 2 jointly point to an inverse relationship between RSPC and HESI. 
Table 2. ARDL Equation Output

\begin{tabular}{|c|c|c|c|c|}
\hline \multicolumn{5}{|c|}{$\begin{array}{l}\text { Dependent Variable: RETAIL SALES PER CA } \\
\text { Method: ARDL } \\
\text { Sample (adjusted): 2003M12 2018M01 } \\
\text { Include observations: } 170 \text { after adjustments } \\
\text { Dependent lags: } 12 \text { (fixed) } \\
\text { Dynamic regressors (12 lags, fixed): EPHESI } \\
\text { Fixed regressors: C }\end{array}$} \\
\hline Variable & Coefficient & Std. Error & t-Statistic & Prob.* \\
\hline $\operatorname{RSPC}(-1)$ & 3.9686 & 0.0819 & 48.4643 & 0.0000 \\
\hline RSPC(-2) & -6.6185 & 0.3299 & -20.0637 & 0.0000 \\
\hline RSPC(-3) & 4.4094 & 0.5954 & 7.4060 & 0.0000 \\
\hline RSPC(-4) & 3.1818 & 0.5694 & 5.5880 & 0.0000 \\
\hline RSPC(-5) & -9.7718 & 0.5420 & -18.0293 & 0.0000 \\
\hline RSPC(-6) & 8.9736 & 0.9684 & 9.2659 & 0.0000 \\
\hline $\operatorname{RSPC}(-7)$ & -2.2141 & 0.9770 & -2.2661 & 0.0249 \\
\hline RSPC(-8) & -3.6810 & 0.5518 & -6.6704 & 0.0000 \\
\hline RSPC(-9) & 4.7568 & 0.5646 & 8.4250 & 0.0000 \\
\hline RSPC(-10) & -2.7629 & 0.5980 & & 0.0000 \\
\hline RSPC (-11) & 0.8880 & 0.3348 & 2.6521 & 0.0089 \\
\hline RSPC(-12) & -0.1369 & 0.0838 & -1.6331 & 0.1046 \\
\hline HESI & -0.1229 & 0.1159 & -1.0599 & 0.2910 \\
\hline HESI(-1) & 0.3132 & 0.1827 & 1.7140 & 0.0887 \\
\hline HESI(-2) & -0.2447 & 0.1859 & -1.3167 & 0.1900 \\
\hline HESI(-3) & 0.0640 & 0.1865 & 0.3430 & 0.7321 \\
\hline HESI(-4) & -0.2777 & 0.1849 & -1.5020 & 0.1353 \\
\hline HESI(-5) & 0.3324 & 0.1830 & 1.8162 & 0.0714 \\
\hline HESI(-6) & -0.0943 & 0.1845 & -0.5112 & 0.6100 \\
\hline HESI(-7) & -0.0731 & 0.1840 & -0.3971 & 0.6919 \\
\hline HESI $(-8)$ & 0.4094 & 0.1819 & 2.2505 & 0.0259 \\
\hline $\operatorname{HESI}(-9)$ & -0.5014 & 0.1821 & -2.7527 & 0.0067 \\
\hline HESI(-10) & 0.3106 & 0.1832 & 1.6952 & 0.0922 \\
\hline $\operatorname{HESI}(-11)$ & -0.3562 & 0.1789 & -1.9909 & 0.0484 \\
\hline HESI(-12) & 0.2118 & 0.1110 & 1.9082 & 0.0583 \\
\hline $\mathrm{C}$ & 8.5322 & 3.1834 & 2.6803 & 0.0082 \\
\hline \multicolumn{2}{|c|}{ R-squared 0.9996} & \multicolumn{3}{|c|}{ Mean dependent var. $1,187.33$} \\
\hline \multicolumn{2}{|c|}{ Adjusted R-squared 0.9996} & \multicolumn{3}{|c|}{ S.D. dependent var 53.984} \\
\hline \multicolumn{2}{|c|}{ S.E. of regression 1.1173} & \multicolumn{3}{|c|}{ Akaike info criterion 3.1995} \\
\hline \multicolumn{2}{|c|}{ Sum squared resid 179.75} & \multicolumn{3}{|c|}{ Schwarz criterion 3.6791} \\
\hline \multicolumn{2}{|c|}{ Log likelihood -245.96 } & \multicolumn{3}{|c|}{ Hannan-Quinn criter. 3.3941} \\
\hline \multicolumn{2}{|c|}{ F-statistic $15,776.4$} & \multicolumn{3}{|c|}{ Durbin-Watson stat 2.0165} \\
\hline \multicolumn{2}{|c|}{ Prob(F-statistic) 0.0000} & \\
\hline
\end{tabular}


*Note: p-values and any subsequent tests do not account for model selection.

Table 3. ARDL Error Correction Equation Output

\begin{tabular}{|c|c|c|c|c|}
\hline \multicolumn{5}{|c|}{$\begin{array}{l}\text { ARDL Error Correction Regression } \\
\text { Dependent Variable: D(RSPC) } \\
\text { Selected Model: ARDL(12,12) } \\
\text { Sample (adjusted): 2003M12 2018M01 } \\
\text { Included observations: } 170 \\
\text { ECM Regression } \\
\text { Case 2: Restricted Constant and No Trend }\end{array}$} \\
\hline Variable & Coefficient & Std. Error & t-Statistic & Prob. \\
\hline $\mathrm{D}(\mathrm{RSPC}(-1))$ & 2.9757 & 0.0806 & 36.9011 & 0.0000 \\
\hline $\mathrm{D}(\mathrm{RSPC}(-2))$ & -3.6429 & 0.2491 & -14.6222 & 0.0000 \\
\hline $\mathrm{D}(\mathrm{RSPC}(-3))$ & 0.7666 & 0.3512 & 2.1826 & 0.0307 \\
\hline $\mathrm{D}(\mathrm{RSPC}(-4))$ & 3.9483 & 0.2711 & 14.5637 & 0.0000 \\
\hline $\mathrm{D}(\mathrm{RSPC}(-5))$ & -5.8234 & 0.4174 & -13.9522 & 0.0000 \\
\hline $\mathrm{D}(\mathrm{RSPC}(-6))$ & 3.1501 & 0.5872 & 5.3650 & 0.0000 \\
\hline $\mathrm{D}(\mathrm{RSPC}(-7))$ & 0.9361 & 0.4239 & 2.2080 & 0.0288 \\
\hline $\mathrm{D}(\mathrm{RSPC}(-8))$ & -2.7450 & 0.2700 & -10.1650 & 0.0000 \\
\hline $\mathrm{D}(\mathrm{RSPC}(-9))$ & 2.0118 & 0.3512 & 5.7284 & 0.0000 \\
\hline $\mathrm{D}(\mathrm{RSPC}(-10))$ & -0.7511 & 0.2516 & -2.9847 & 0.0033 \\
\hline $\mathrm{D}(\mathrm{RSPC}(-11))$ & 0.1369 & 0.0830 & 1.6505 & 0.1010 \\
\hline $\mathrm{D}(\mathrm{HESI})$ & -0.1229 & 0.1117 & -1.1003 & 0.2731 \\
\hline D(HESI(-1)) & 0.2193 & 0.1149 & 1.9090 & 0.0582 \\
\hline $\mathrm{D}(\operatorname{HESI}(-2))$ & -0.0254 & 0.1161 & -0.2186 & 0.8273 \\
\hline $\mathrm{D}(\operatorname{HESI}(-3))$ & 0.0386 & 0.1163 & 0.3318 & 0.7405 \\
\hline $\mathrm{D}(\mathrm{HESI}(-4))$ & -0.2391 & 0.1143 & -2.0927 & 0.0381 \\
\hline $\mathrm{D}(\operatorname{HESI}(-5))$ & 0.0933 & 0.1150 & 0.8109 & 0.4188 \\
\hline D(HESI $(-6))$ & -0.0011 & 0.1147 & -0.0094 & 0.9925 \\
\hline $\mathrm{D}(\operatorname{HESI}(-7))$ & -0.0742 & 0.1144 & -0.6481 & 0.5180 \\
\hline D(HESI $(-8))$ & 0.3352 & 0.1124 & 2.9836 & 0.0033 \\
\hline $\mathrm{D}(\operatorname{HESI}(-9))$ & -0.1661 & 0.1139 & -1.4591 & 0.1467 \\
\hline $\mathrm{D}(\operatorname{HESI}(-10))$ & 0.1444 & 0.1126 & 1.2832 & 0.2015 \\
\hline D(HESI $(-11))$ & -0.2118 & 0.1070 & -1.9797 & 0.0496 \\
\hline CointEq(-1)* & -0.0070 & 0.0024 & -2.9480 & 0.0037 \\
\hline R-squared & 0.9924 & Mean depen & t var & 0.6612 \\
\hline Adjusted R-squared & 0.9912 & S.D. depend & var & 11.827 \\
\hline S.E. of regression & 1.1096 & Akaike info & erion & 3.1760 \\
\hline Sum squared resid & 179.75 & Schwarz crit & & 3.6187 \\
\hline Log likelihood & -245.96 & Hannan-Qui & criter. & 3.3556 \\
\hline Durbin-Watson stat & 2.0165 & & & \\
\hline
\end{tabular}




\begin{tabular}{|l|l|l|l|l|}
\hline \multicolumn{2}{|l|}{ F-Bounds Test } & \multicolumn{3}{|l|}{ Null Hypothesis: No levels relationship } \\
\hline Test Statistic & Value & Signif. & I(0) & I(1) \\
\hline F-statistic & 2.857 & $10 \%$ & 3.02 & 3.51 \\
\hline k & 1 & $5 \%$ & 3.62 & 4.16 \\
\hline & & $2.5 \%$ & 4.18 & 4.79 \\
\hline & & $1 \%$ & 4.94 & 5.58 \\
\hline
\end{tabular}

Table 3 summarizes the short-run error correction equation output. Many of the parameters estimated for the first differences of the lags of the two variables do not surpass the standard 5-percent significance threshold. That is due, in part, to multicollinearity resulting from including 12 lags of each variable in the specification. The error correction term is negative as hypothesized and it has a small standard error associated with it. At -0.007 , it implies that deviations from equilibrium require approximately 142 months (nearly 12 years) to fully dissipate.

Table 4. ARDL Long Run Equation

\begin{tabular}{|c|c|c|c|c|}
\hline \multirow{5}{*}{\multicolumn{5}{|c|}{$\begin{array}{l}\text { ARDL Long Run Form and Bounds Test } \\
\text { Dependent Variable: D(RSPC) } \\
\text { Selected Model: ARDL(12,12) } \\
\text { Sample (adjusted): } 2003 \mathrm{M} 12 \text { 2018M01 } \\
\text { Included observations: } 170\end{array}$}} \\
\hline & & & & \\
\hline & & & & \\
\hline & & & & \\
\hline & & & & \\
\hline \multicolumn{5}{|c|}{$\begin{array}{c}\text { Levels Equation } \\
\end{array}$} \\
\hline Variable & Coefficient & Std. Error & t-Statistic & Prob. \\
\hline HESI & -4.1280 & 3.1087 & -1.3279 & 0.1863 \\
\hline $\mathrm{C}$ & $1,213.9$ & 21.087 & 57.567 & 0.0000 \\
\hline
\end{tabular}

Table 4 reports the long-run levels results. The slope coefficient for HESI is -4.128 . That implies that a full 1-point increase in HESI leads to a $\$ 4.13$ per month reduction in RSPC. That translates to an aggregate impact of nearly $\$ 3.48$ million in lost monthly commercial activity every the HESI experiences a 1-point increment. The intercept term is $\$ 1,213.90$, which, in concert with the slope parameter, suggests that per capita retail purchases are fairly stable from one month to the next. Although the HESI coefficient may seem small, the elasticity is -0.636 and that magnitude is fairly plausible.

The computed F-statistic for the bounds test is 2.857 . The bounds test null hypothesis is that no cointegration exists between HESI and RSPC. The computed F-statistic is lower than the upper band critical values at every significance level in Table 3. Consequently, the null hypothesis fails to be rejected. That implies that a reliable long-run relationship between HESI and RSPC does not exist. Given the appearance of data in Figure 1, that result is not entirely surprising. It should be noted, however, that fifteen years of monthly data does not 
constitute a very long time span.

\section{Conclusion}

Household economic stress indices (HESI) are measures used to gauge levels of economic distress faced by households in different regions. This study examines potential linkages between one HESI and retail sales per capita (RSPC) in El Paso, Texas. HESI data are available for El Paso from the University of Texas at El Paso Border Region Modeling Project. An inverse relationship is hypothesized to exist between HESI and RSPC.

An autoregressive distributed lag (ARDL) model is estimated using data from January 2001 to December 2018. Fluctuations in the HESI are found to negatively correlated with RSPC. When the index grows by 1 point, total retail sales fall by nearly $\$ 3.548$ million. A statistically reliable long-run relationship is not, however, found to exist between the two series. That may be because fifteen years of data is still a relatively short time span.

Although a reliable long-run statistical relationship between HESI and RSPC is not uncovered, it is possible that a sound short-run linkage exists between these two variables. One method that has been used to quantify short-run relationships among other regional economic variables is linear transfer function autoregressive integrated moving average analysis. Additional testing using that approach may prove useful, in part because it can handle different types of data generating processes.

To date, there have been relatively few empirical analyses of the reliability of HESI variables as gauges of consumer stress in local or regional economies. Additional testing for metropolitan economies other than El Paso may prove useful. For the specific case of El Paso, it may be worthwhile to more closely examine potential short-run linkages between RSPC and HESI. Analyses of the relationships between HESI and other regional variables such as loan demand, air travel, crime, and bankruptcies may help clarify the efficacy of this type of metric.

\section{Acknowledgements}

Financial support for this research was provided by El Paso Water, National Science Foundation Grant DRL-1740695, Texas Department of Transportation ICC 24-0XXIA001, TFCU, the UTEP Center for the Study of Western Hemispheric Trade, the UTEP Campus Office of Undergraduate Research Initiatives, and the Hunt Institute for Global Competitiveness at UTEP. Helpful comments and suggestions were provided by Steven Fullerton and two anonymous referees https://10. https://10..

\section{References}

Akcay, S. (2018). Remittances and Misery Index in Turkey: Is there a Link?. Applied Economics Letters, 25(13), 895-899. https://10.1080/13504851.2017.1380284

Barro, R. J. (1999). Reagan vs. Clinton: Who's the Economic Champ?. Business Week, 22.

BEA. (2019). Personal Consumption Expenditures Price Index. Washington, DC: United States Bureau of Economic Analysis. 


\section{Macrothink}

Business and Economic Research ISSN 2162-4860 2020, Vol. 10, No. 3

CEDBR. (2017). Misery Index up from 2016. Wichita, KS: Wichita State University Center for Economic Development and Business Research.

CE. (2010). How Economists Convert Quarterly Data into Monthly: Cubic Spline Interpolation. Des Moines, WA: Columbia Economics.

Dadgar, Y., \& Nazari, R. (2018). The Impact of Economic Growth and Good Governance on Misery Index in Iranian Economy. European Journal of Law and Economics, 45(1), 175-193. https://10.1007/s10657-012-9327-2

Di Tella, R., MacCulloch, R. J., \& Oswald, A. J. (2001). Preferences over Inflation and Unemployment: Evidence from Surveys of Happiness. American Economic Review, 91(1), 335-341. https://10.1257/aer.91.1.335

Dye, R. A., \& Sutherland, C. (2009). A New Metric to Gauge Household Economic Stress: Improving on the Misery Index. Business Economics, 44(2), 109-113.

https://10.1057/be.2009.3

Farvaque, E., \& Jean, N. (2007). Economic Analysis of Local Elections: A Case Study of France, 1983-2001. Revue d'Économie Régionale \& Urbaine, 5, 945-961.

https://10.3917/reru.075.0945

FRBD. (2019). El Paso Real Retail Sales. Dallas, TX: Federal Reserve Bank of Dallas.

Fullerton, T. M., Jr., Nazarian, A. D., Fullerton, S. L., \& Olivas, S. Jr. (2019). Reaching the Apex? Borderplex Business Barometer, 3(5), 1-44.

Grinstein-Weiss, M., Key, C., Guo, S., Yeo, Y. H., \& Holub, K. (2013). Homeownership and Wealth among Low- and Moderate-Income Households. Housing Policy Debate, 23(2), 259-279. https://10.1080/10511482.2013.771786

Hanke, S. H. (2014). Measuring Misery around the World. Washington, DC: Cato Institute.

Hortalá i Arau, J., \& Rey Miró, D. (2011). Relevancia del Índice de Malestar Económico. Cuadernos de Economía (Spain), 34(96), 162-169. https://10.1016/S0210-0266(11)70016-4

Hufbauer G., Kim, J., \& Rosen, H. (2008). The Augmented Misery Index. Washington, DC: Peterson Institute for International Economics.

Layton, A. P. (1992). An Estimated Australian Macroeconomic Misery Index. Economic Record, 68(201), 143-161. https://10.1111/j.1475-4932.1992.tb01757.x

Lean, H. H., \& Smyth, R. (2011). Will Obama's Economic Stimulus Package be Effective? Evidence from the Misery Index. Applied Economics Letters, 18(5), 493-495. https://10.1080.13504851003724259

Lovell, M. C., \& Tien, P. L. (2000). Economic Discomfort and Consumer Sentiment. Eastern Economic Journal, 26(1), 1-8.

Pesaran, M. H., Shin, Y., Richard, R., \& Smith, J. (2001). Bounds Testing Approaches to the Analysis of Level Relationships. Journal of Applied Econometrics, 16, 289-326. 
https://10.1002/jae.616

Tang, C. F., \& Lean, H. H. (2009). New Evidence from the Misery Index in the Crime Function. Economics Letters, 102(2), 112-115. https://10.1016/j.econlet.2008.11.026

\section{Copyright Disclaimer}

Copyright for this article is retained by the author(s), with first publication rights granted to the journal.

This is an open-access article distributed under the terms and conditions of the Creative Commons Attribution license (http://creativecommons.org/licenses/by/4.0/). 